\title{
Return to sports after ACL reconstruction: a paradigm shift from time to function
}

\author{
Wolf Petersen $^{1} \cdot$ Christian Fink $^{2,3} \cdot$ Sebastian Kopf $^{4}$
}

Published online: 16 May 2017

(C) European Society of Sports Traumatology, Knee Surgery, Arthroscopy (ESSKA) 2017

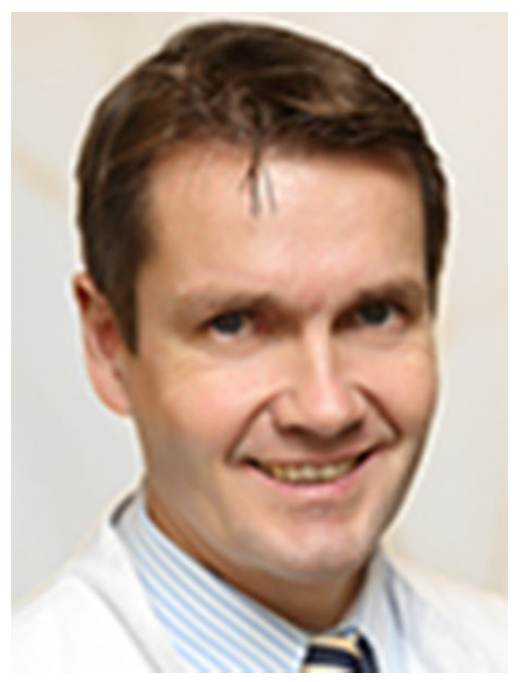

Wolf Petersen

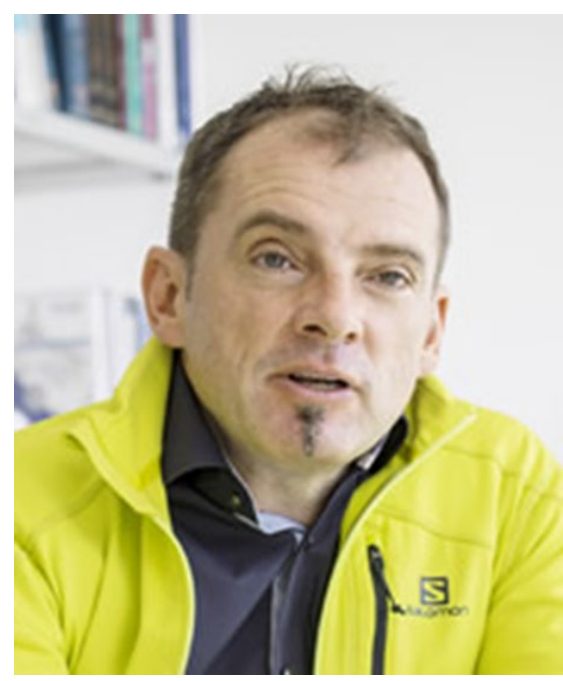

Christian Fink

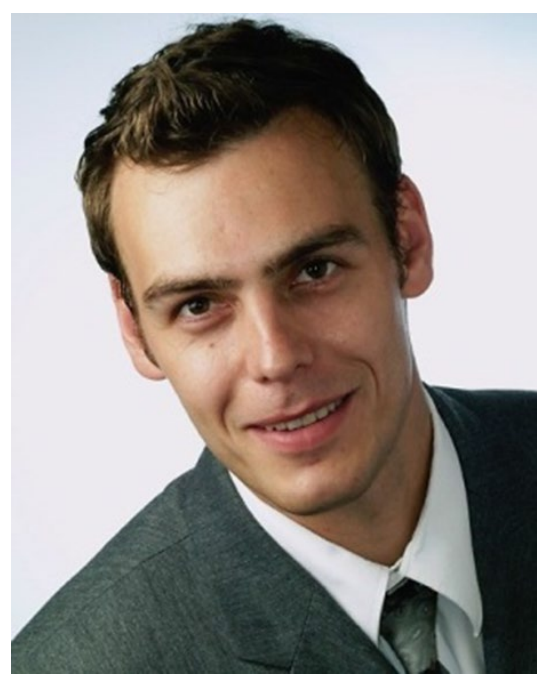

Sebastian Kopf
Injuries of the anterior cruciate ligament occur frequently in sports and can result in a decrease or even loss of activity and thus endangering the career of athletes [2]. Sports at risk are soccer, football, basketball, handball, judo or alpine

Wolf Petersen

wolf.petersen@pgdiakonie.de

1 Klinik für Orthopädie und Unfallchirurgie, Martin-LutherKrankenhaus, Caspar-Theyss-Straße 27-33, 14193 Berlin, Germany

2 Gelenkpunkt - Sports and Knee Surgery, Innsbruck, Austria

3 Research Unit for Orthopedic Sports Medicine and Injury Prevention, ISAG/UMIT, Hall, Austria

4 Center for Musculoskeletal Surgery, Charité - University Medicine Berlin, Berlin, Germany skiing. The cause is often a non-contact trauma, e.g. during landing a jump or performing a sudden twist.

Anterior cruciate ligament reconstruction (ACL-R) with an autologous tendon graft is the treatment of choice for athletes with symptomatic instability. With this surgical procedure, the function of the injured knee joint can be restored providing the basis for a return to the preinjury activity level. Various studies also demonstrated a protective effect of ACL-R on the incidence of secondary meniscus and cartilage lesions [5]. There has been a controversy about the success of ACL-R to prevent or slow down osteoarthritis (OA) compared to conservative treatment of an ACL tear [12]. However, a recent systematic review showed that the risk of an early onset of OA is reduced by ACL-R [1].

Unfortunately, some studies described high re-rupture rates after ACL reconstruction [11]. An ACL rupture also 
often occurs on the previously uninjured side. One reason for the occurrence of a re-rupture is a too early return to sports. General opinion of most surgeons is that time after surgery is the main criterion to decide about the return to practice or competition of athletes. This opinion is supported by the literature, e.g. in a systematic review about return to sports, time was the main criterion for return to sports of most of the included studies [3]. There is controversy about the best time point to allow the athlete to return to sports especially on a competitive level: in most studies of the above-mentioned review, a postoperative period of six months was suggested as to be sufficient to have the athlete refrain from her or his original activity [3]. Probably the results of an animal experiment were the basis for this recommendation. This study showed that the remodelling of the ACL grafts is completed after approximately 6 months. However, in a recent survey conducted among the instructors of arthroscopy of the German-speaking Society of Joint Surgery (AGA), the majority of the included surgeons considered a time interval of 6-10 months as to too early for a safe return [15]. Avoiding a return to sports on a competitive level for a longer time period is supported by a biopsy study, in which remodelling (=ligamentization) of human ACL grafts took up to 2 years [14]. These findings suggest that the majority of patients returns to sports at a time when graft remodelling has not yet been completed. Interestingly, clinical evidence strongly indicates that the highest risk of ACL re-ruptures is within the first two years after reconstruction, especially in young high-level athletes [11]. These authors stated that the incidence of ACL re-ruptures significantly decreased if athletes delayed their return to high-level activity until 2 years after ACL-R [11]. However, a time period of 2 years from surgery to return to sports could mean the end of the career for many professional athletes. Because it seems unrealistic to keep athletes for 2 years away from their sports activity trying to achieve their preinjury activity level and waiting for complete graft remodelling, grafts should be rather protected by a well neuromuscular stabilized joint. Traditionally, postoperative rehabilitation was divided into fixed time-based phases.

However, in recent years, functional criteria have been emphasized to better characterize the neuromuscular condition of the knee joint $[7,8]$. These criteria relate to joint function, strength, functional stability, proprioception, agility and the occurrence of risk-movement patterns. All of these factors are severely influenced by the initial knee injury, the surgery and the rehabilitation before and after ACL-R. During the rehabilitation period, all of these functional deficits have to be restored. The duration by which an athlete is able to advance in his or her programme is extremely variable and dependent on the extent of the injury, the time devoted for training and rehabilitation as well as constitutional variations. Time-based criteria are therefore questionable not only to define the time of the final comeback, but also to progress to the next level of rehabilitation.

Particularly with regard to a further contralateral ACL injury, high attention should be paid to the so-called risk-movement patterns [10, 17]. These are risk factors which are in general present bilaterally and were also present before the first knee injury. The risk motion patterns include, for example, the functional valgus position and reduced flexion angle of the knee joint when landing a jump. A comprehensive rehabilitation programme has to take all these factors into account, and athletes at risk have to be identified and treated.

Finally, we have to be aware that "return to activity", especially in professional sports, does not necessarily mean a "problem and pain free return". Although athletes perform on a high or preinjury level, they still may experience some limitations. On the other hand, an athlete may never return to his or her preinjury level due to reasons that are unrelated to the knee. Therefore, it is questionable whether "return to sports" is really a good criterion to judge the outcome of ACL-R. And although it is an important parameter, "success" of ACL-R is still a very complex issue which involves comprehensive and meticulous subjective as well as objective evaluation. The current issue of KSSTA reflects the current scientific discussion about this hot topic in sports medicine. In this very interesting issue, several of the included articles are concerned with the decision about the return to sports. For example, Sousa et al. [16] tried to answer the question whether excellent 6-month strength and function following ACL reconstruction predict midterm outcomes. Trigsted et al. examined landing mechanics during single hop for distance test following ACL reconstruction compared to healthy controls [18]. Behrend et al. [4] studied joint awareness after ACL-R: patient-reported outcomes measured with the Forgotten Joint Score. Nyland et al. [13] examined permanent knee sensorimotor system changes following ACL Injury and Surgery. It is also an interesting question how different grafts and reconstruction techniques affect recovery and return to sports. Engelen van Melick et al. [6] evaluated the functional performance using BTB grafts, while Iriuchishima et al. [9] studied muscle recovery following ACL-R with a quadriceps tendon graft.

All of these studies will further elucidate the question when an athlete can return safely to his preinjury activities.

\section{References}

1. Ajuied A, Wong F, Smith C, Norris M, Earnshaw P et al (2014) Anterior cruciate ligament injury and radiologic progression of knee osteoarthritis: a systematic review and meta-analysis. Am J Sports Med 42:2242-2252 
2. Ardern CL, Webster KE, Taylor NF, Feller JA (2011) Return to sport following anterior cruciate ligament reconstruction surgery: a systematic review and meta-analysis of the state of play. Br J Sports Med 45:596-606

3. Barber-Westin SD, Noyes FR (2011) Factors used to determine return to unrestricted sports activities after anterior cruciate ligament reconstruction. Arthroscopy 27(12):1697-1705

4. Behrend H, Zdravkovic V, Giesinger JM, Giesinger K (2017) Joint awareness after ACL reconstruction: patient-reported outcomes measured with the forgotten joint score-12. Knee Surg Sports Traumatol Arthrosc. doi:10.1007/s00167-016-4357-x

5. Brambilla L, Pulici L, Carimati G, Quaglia A, Prospero E et al (2015) Prevalence of associated lesions in anterior cruciate ligament reconstruction: correlation with surgical timing and with patient age, sex, and body mass index. Am J Sports Med 43:2966-2973

6. Engelen-van Melick N, van Cingel RE, van Tienen TG, Nijhuisvan der Sanden MW (2017) Functional performance 2-9 years after ACL reconstruction: cross-sectional comparison between athletes with bone-patellar tendon-bone, semitendinosus/gracilis and healthy controls. Knee Surg Sports Traumatol Arthrosc. doi:10.1007/s00167-015-3801-7

7. Herbst E, Hoser C, Hildebrandt C, Raschner C, Hepperger C et al (2015) Functional assessments for decision-making regarding return to sports following ACL reconstruction. Part II: clinical application of a new test battery. Knee Surg Sports Traumatol Arthrosc 23:1283-1291

8. Hildebrandt C, Müller L, Zisch B, Huber R, Fink C et al (2015) Functional assessments for decision-making regarding return to sports following ACL reconstruction. Part I: development of a new test battery. Knee Surg Sports Traumatol Arthrosc 23:1273-1281

9. Iriuchishima T, Ryu K, Okano T, Suruga M, Aizawa $\mathrm{S}$ et al (2017) The evaluation of muscle recovery after anatomical single-bundle ACL reconstruction using a quadriceps autograft. Knee Surg Sports Traumatol Arthrosc. doi:10.1007/ s00167-016-4124-Z
10. Lephart SM, Ferris CM, Fu FH (2002) Risk factors associated with noncontact anterior cruciate ligament injuries in female athletes. Instr Course Lect 51:307-310

11. Nagelli CV, Hewett TE (2017) Should return to sport be delayed until 2 years after anterior cruciate ligament reconstruction? Biological and functional considerations. Sports Med 47(2):221-232

12. Nagelli CV, Cook JL, Kuroki K, Bozynski C, Ma R et al (2016) Does anterior cruciate ligament innervation matter for joint function and development of osteoarthritis? J Knee Surg. doi:10.105 5/s-0036-1592145

13. Nyland J, Gamble C, Franklin T, Caborn DN (2017) Permanent knee sensorimotor system changes following ACL injury and surgery. Knee Surg Sports Traumatol Arthrosc. doi:10.1007/ s00167-017-4432-y

14. Pauzenberger L, Syré S, Schurz M (2013) "Ligamentization" in hamstring tendon grafts after anterior cruciate ligament reconstruction: a systematic review of the literature and a glimpse Into the future. Arthroscopy 29(10):1712-1721

15. Petersen W, Zantop T (2013) Return to play following ACL reconstruction: survey among experienced arthroscopic surgeons (AGA instructors). Arch Orthop Trauma Surg 133:969-977

16. Sousa PL, Krych AJ, Cates RA, Levy BA, Stuart MJ et al (2017) Return to sport: does excellent 6-month strength and function following ACL reconstruction predict midterm outcomes? Knee Surg Sports Traumatol Arthrosc. doi:10.1007/ s00167-015-3697-2

17. Sugimoto D, Myer GD, Barber Foss KD, Pepin MJ, Micheli LJ et al (2017) Critical components of neuromuscular training to reduce ACL injury risk in female athletes: meta-regression analysis. Br J Sports Med 50:1259-1266

18. Trigsted SM, Post EG, Bell DR (2017) Landing mechanics during single hop for distance in females following anterior cruciate ligament reconstruction compared to healthy controls. Knee Surg Sports Traumatol Arthrosc. doi:10.1007/s00167-015-3658-3659 